\title{
1. Introduction to Technology and Corporate Law
}

\author{
Andrew Godwin, Pey Woan Lee and \\ Rosemary Teele Langford
}

\subsection{CONTEXT, CONTRIBUTION AND STRUCTURE}

Technology is ubiquitous and palpable in all aspects of modern life. This phenomenon is now all the more entrenched as Covid-19 has rapidly accelerated digital transformation, dramatically and permanently altering the manner of our work, business and social activities. As the most common business form, the corporation is situated at the forefront of this revolution. Businesses must inevitably innovate to protect and acquire market share. Indeed, the adoption of technology to these ends is increasingly an existential necessity given the remarkable shifts in consumption patterns and in sales and distribution channels. When they succeed, efforts to innovate have spawned novel activities and business models that raise interesting and complex issues as to legality and regulation. Correspondingly, a growing body of legal scholarship has emerged to address these challenges. Consistent with its hegemony in innovating and adopting technological solutions, the financial sector has generated the most conspicuous surge in such scholarship. Much attention has been drawn, for instance, to the rise of FinTech, RegTech and crypto-assets as innovations that are rapidly and continuously reshaping our financial and economic landscape.

More recently, the tidal waves of technological advances have also sparked critical reflections on their potential impact on various aspects of corporate activities. Significantly, the current technological age is characterised not by a single dominant technology but by an array of technologies including blockchain, artificial intelligence (AI), machine learning, robotics, big data analytics and cloud computing, the effects of which are further intensified by easy access to global connectivity (Internet) and high-performance computing. The convergence of these technologies produces 'amplification effects'; that is, they 'interact with each other and create synergies that greatly [increase] 
their social impact and effects'. ${ }^{1}$ In turn, these amplification effects drive the exponential growth of other new technologies and applications, further exacerbating the gap between current realities and a governance system designed for a bygone age.

This book builds on, and departs from, current literature through its focus on corporate regulation and governance in the context of Asia and Australasia. Despite this jurisdictional focus, the themes and challenges raised in the chapters transcend international boundaries and confront the international community as a whole. The book's critical analysis of the impact of technology and innovation on corporate regulation and governance is of particular relevance to the US, Canada and the UK, which, like the Australasian jurisdictions referred to in this book, have common law systems as their basis.

It is hoped that this publication will contribute usefully to the discourse and ongoing debate about the impact of technology on corporate law and regulation. As implied throughout this book, a critical issue is the extent to which advances in technology could or should be accommodated within the existing legal and regulatory framework. A related issue is 'technological exceptionalism'; namely, whether and to what extent new technologies generate such fundamental social change as to transform legal rules and frameworks, and whether law and technology are in fact intertwined such that each is a factor in the construction and development of the other. ${ }^{2}$ It appears undeniable that modifications to the existing legal and regulatory framework will be necessary to reflect the various ways in which technology is facilitating or disrupting traditional forms of operation and systems of governance. The chapters in this book, however, suggest that it is premature to predict the ultimate obsolescence of human-driven companies and corporate law as a result of technology and that it is likely that technology will continue to operate alongside, and enhance, the existing framework.

The chapters in this book are divided into four parts by reference to the following themes: (1) corporate form; (2) board governance; (3) governance democratisation; and (4) data enhancements and alternative models for 'corporate' governance.

1 Mark Fenwick and Erik PM Venmeulen, 'Technology and Corporate Governance: Blockchain, Crypto, and Artificial Intelligence' (2019) 48 Texas Journal of Business Law 1,3 .

2 See, eg, David Friedman, 'Does Technology Require New Law?' (2001) 25 Harvard Journal of Law and Policy 71; Meg Leta Jones, 'Does Technology Drive Law? The Dilemma of Technological Exceptionalism in Cyberlaw' (2018) University of Illinois Journal of Law, Technology and Policy 248. 


\subsection{INNOVATION, TECHNOLOGY AND CORPORATE LAW}

A survey of the emerging body of literature examining technology and corporate law reveals several themes around which current academic commentary is organised. A prominent theme concerns the extent to which traditional governance models should be overhauled or, alternatively, retrofitted to accommodate the social and business changes wrought by technological developments. One aspect of this broad theme is the impact of technology on the corporate form, which Watson explores in Chapter 2 of this book. She revisits the concept of the corporation as a legal fiction and suggests that the AI board is simply an evolution of a board comprising natural persons.

Indeed, questions concerning the future of corporate management as AI increases in sophistication and dominance have sparked considerable academic interest. For instance, Petrin hypothesises that 'the multi-member board is set to vanish once AI is able to replicate the benefits of group decision-making by humans and exceed both the speed and quality of decisions made by human teams'. ${ }^{3}$ On this view, an AI director (essentially AI software) would be selected and 'appointed' by shareholders in place of the traditional board. ${ }^{4}$ Apart from the superior quality of its decisions, AI software would also shift the locus of corporate governance away from its traditional focus on managerial misbehaviour, as software would operate without self-interest and hence eliminate agency costs altogether. ${ }^{5}$

Likewise, Armour and Eidenmüeller foresee the rapid rise of AI-adoption in corporate management and analyse its implications in two broad phases. ${ }^{6}$ In the immediate and foreseeable term, AI will principally be used to assist with and augment human decisions. That is likely to lead to a reduction of standard agency costs as human involvement decreases, but overall agency costs may not decrease as new agency costs will be incurred in connection with 'data governance'; namely, 'the selection and training of [machine learning]

\footnotetext{
3 Martin Petrin, 'Corporate Management in the Age of AI' (2019) Columbia Business Law Review 965, 1002.

4 Ibid 1003. This assumes that the relevant laws do not require directors to be natural persons and that AI software is capable of exercising the rights and powers of legal personality. These are currently matters of intense debate: see Florian Möslein, 'Robots in the Boardroom: Artificial Intelligence and Corporate Law' in Woodrow Barfield and Ugo Pagalio (eds), Research Handbook on the Law of Artificial Intelligence (Edward Elgar, 2018) 663-6.

5 Petrin (n 3) 1005.

6 John Armour and Horst Eidenmüeller, 'Self-Driving Corporations?' (2020) 10 Harvard Business Law Review 87.
} 
applications and the alignment of [machine learning] predictions with key corporate goals'. ${ }^{7}$ Correspondingly, it will become increasingly crucial for boards to have the relevant technical expertise to engage in adequate oversight for data governance. ${ }^{8}$ In the long term, however, Armour and Eidenmüeller envisage the eventual evolution of 'self-driving corporations', beginning first with 'self-driving subsidiaries' - corporations with limited functions that are therefore more amenable to automated management. ${ }^{9}$ The impetus for such development lies in the significant productivity gains that result when AI makes better decisions than humans.

Similar to Petrin, Armour and Eidenmüeller predict a shift of regulatory focus away from classic agency issues. ${ }^{10}$ However, they foresee increased regulation on corporate goal-setting functions. Since algorithms are designed to achieve pre-determined goals, what goals may legitimately be pursued becomes a significant corporate governance question. ${ }^{11}$ In addition, autonomous corporations are likely to exacerbate the 'asymmetry of risks and liability'12 as a fully self-driving corporation may inflict serious damage that is not properly compensated. This is because the corporation is often 'judgment proof' by reason of having insufficient assets. Redress through managerial accountability would also be limited given the lack of human involvement in the decision-making chain. To correct this asymmetry, alternative liability regimes in the form of general shareholder liability or mandatory insurance against algorithmic failures may have to be considered. ${ }^{13}$

In a related vein, much excitement has arisen over the promise of blockchain or distributed ledger technology (DLT) ${ }^{14}$ in delivering solutions for corporate governance issues. Characterised by decentralisation and immutability, DLT enhances the speed, costs, transparency and (data) integrity of transactions. This theme is explored in this book by Gurrea-Martínez and Remolina (Chapter 9) in the context of initial coin offerings and by Abdussalam and Rahim (Chapter 13) in the context of decentralised autonomous business networks. Characterised by decentralisation and immutability, DLT enhances the speed, costs, transparency and (data) integrity of transactions. Together, these

\footnotetext{
7 Ibid 102.

8 Ibid 99-103.

9 Ibid 106-7.

10 Since algorithms can act neither in good faith nor in bad faith but only in accordance with their given goals as programmed: ibid 108 .

${ }_{11}$ Ibid. See also Christopher M Bruner, 'Distributed Ledgers, Artificial Intelligence and the Purpose of the Corporation' (2020) 79 Cambridge Law Journal 431.

12 Armour and Eidenmüeller (n 6) 107.

13 Ibid 112.

14 In this chapter, we use the terms DLT and blockchain interchangeably though blockchain is, more accurately, just a specific application of DLT.
} 
attributes could radically transform current corporate governance structures and processes. In the context of securities trading, David Yermack envisages that a trading and tracking system supported by DLT 'could profoundly alter the power of managers, shareholders, lenders, regulators, and third party experts who interact in the corporate governance area' ${ }^{15}$ One prominent manifestation of that is explored in this book by Kourabas (Chapter 10), who considers the opportunity that equity crowdfunding presents to raise finance from a widely dispersed group of shareholders.

DLT may also bring about greater ownership transparency and improve liquidity, making it easier for investors to enter and exit markets more quickly. In turn, that may cause investors to favour exit, rather than negotiation or voting, as the primary means of influencing management. ${ }^{16}$ Increased transparency may also expose managers to greater scrutiny by their boards and shareholders, minimising the effectiveness of equity-based incentives to encourage managerial performance and accountability. ${ }^{17}$ More generally, the 'unprecedented transparency' afforded by blockchain technology could 'reduce the opportunity for rent-seeking or corrupt behaviour by regulators, exchanges and listed companies' ${ }^{18}$ Further, Yermack hypothesises that a firm could in future choose to post all its ordinary transactions on a public blockchain, so that all its 'routine accounting data could be recorded permanently with a time stamp, preventing it from being altered ex-post' ${ }^{19}$ The disintermediation that follows could lead to substantial cost savings since firms would no longer require the services of accountants and other financial intermediaries. ${ }^{20}$

The rise of disintermediation in modern businesses has also cast doubt on the continued relevance of shareholder primacy as the cornerstone of contemporary corporate governance. Fenwick et al argue, for instance, that the success of 'platform companies' demonstrates the need for a new governance structure to promote innovative businesses that create long-term value. ${ }^{21}$ Platform companies are community-driven companies that 'leverage networked technologies

15 David Yermack, 'Corporate Governance and Blockchains' (2017) Review of Finance 7, 28. See also Anne Lafarre and Christoph van der Elst, 'Blockchain Technology for Corporate Governance and Shareholder Activism' (Working Paper No. 390/2018, European Corporate Governance Institute, 8 March 2018).

16 Yermack (n 15) 20.

17 Ibid 20-1.

18 Ibid 8.

19 Ibid 24-5.

20 Ibid 24-7.

21 Mark Fenwick, Joseph McCahery and Erik Vermeulen, "The End of "Corporate" Governance: Hello “Platform” Governance' (2019) 20 European Business Organization Law Review 171. 
to promote economic exchange, transfer information and connect people' ${ }^{22}$ Utilising data and algorithms to replace middlemen, such companies tend to be 'flatter, unmediated organisations in which the best-idea-wins culture prevails'. ${ }^{23}$ Existing corporate governance characterised by centralisation, vertical hierarchies and shareholder primacy is no longer viable as it tends to breed short-termism and inhibit innovation. ${ }^{24}$ Instead, a new governance model should be developed that enables unmediated communications with all stakeholders ${ }^{25}$ and facilitates decentralisation through the adoption of technology. ${ }^{26}$ Directors appointed under this model are also expected to provide 'unmediated and relevant input from the market'. ${ }^{27}$

Such optimistic conjectures of modern technology as a panacea for classic corporate governance problems are not, however, shared by all commentators. In a recent publication, Enriques and Zetzsche issued a clarion call for greater realism in assessing the impact of technology on corporate governance. They reject the radical prediction that DLT will enable full transparency leading to disintermediation that allows shareholders to exercise direct oversight over a firm's transactions. ${ }^{28}$ Nor do they think that board functions will, in the foreseeable future, be automated to such an extent as to displace human directors. A similar reservation is expressed in this book by Bird and Locke (Chapter 3), who foresee that human directors will continue to have crucial roles in corporate management even as they predict the advent of 'fused boards' comprising human actors assisted extensively by AI.

For Enriques and Zetzsche, excessively sanguine predictions as to the impact of technology are erroneously predicated on the 'tech nirvana fallacy, that is, the tendency to contrast a perfect technology-enhanced but hypothetical world with the real, imperfect one in which humans currently live'. ${ }^{29}$ In reality,

\section{Ibid 175.}

23 Mark Fenwick, Wulf Kaal and Erik Vermeulen, 'The Unmediated and Tech-Driven Corporate Governance of Today's Winning Companies' (2019) 16 New York University Journal of Law and Business 75, 76.

24 Fenwick et al (n 21) 181-3.

25 Principally by leveraging on social media in the sense of 'decentralization and democratization of the firm by sharing and vocalizing the ins-and-outs of its inner workings': see Fenwick et al (n 23) 103 n 85.

26 Ibid 116-20.

$27 \quad$ Ibid 112.

28 Luca Enriques and Dirk Andreas Zetzsche, 'Corporate Technologies and the Tech Nirvana Fallacy’ (Working Paper No. 457/2019, European Corporate Governance Institute, 25 March 2020).

29 Ibid 19. See also Kelvin Low and Eliza Mik, 'Pause the Blockchain Legal Revolution' (2020) 69 International and Comparative Law Quarterly 135 for a general discussion of the mistaken conceptual assumptions that underpin the hype on DLT as a revolutionary tool for resolving legal problems. 


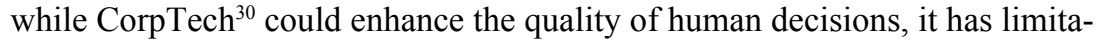
tions that render it incapable of performing the full range of board functions. A significant limitation lies in the fact that algorithms are data-dependent, so that their predictive capabilities are only as good as the quality of the data on which they were trained ${ }^{31}-a$ theme that Brand explores in Chapter 4 of this book. But even assuming that the data were appropriate and bias-free, the backward-orientation of data dependency means that algorithms are unsuited for rendering decisions in novel settings. Further, algorithms are (based on current technology) incapable of resolving ethical and discretionary decisions in conditions of considerable uncertainty. ${ }^{32}$

Moreover, Enriques and Zetzsche observe that there are traits inherent in corporate governance that cannot be eradicated by technology..$^{33}$ For example, CorpTech alone cannot bridge the contractual gaps that inevitably exist between stakeholders; nor can it eliminate conflicts of interests or informational asymmetry. So long as a firm's assets are controlled by human agents, conflicts of interest and informational asymmetry would persist in the design (or code) of CorpTech. For all these reasons, CorpTech is unlikely to render obsolete the core functions of the board. Rather, what becomes more pressing in an environment dominated by CorpTech is to adapt extant corporate governance framework to guard against the risks of deploying CorpTech. In particular, it would be pertinent to ask 'who controls the CorpTech within the firm' and whether the controller would select a technological design or code that optimises shareholder interests. ${ }^{34}$ To that end, the authors suggest that firms should extend the remit of their existing committees to include - or establish tech committees with - oversight of CorpTech. ${ }^{35}$ They also recommend that

30 Enriques and Zetzsche define 'CorpTech' to comprise 'all solutions relating to corporate governance broadly defined, including tools to set executive compensation, identify candidates for top positions within the organization, facilitate investor relations, corporate voting and the internal workings of the board of directors, manage risk and enhance compliance functions': Enriques and Zetzsche (n 28) 4.

31 Ibid 24-7.

32 Ibid 27-9. See also Sergio Alberto Gramitto Ricci, 'Artificial Agents in Corporate Boardrooms' (2020) 105 Cornell Law Review 870. According to this view, since AI agents lack conscience and consciousness, they cannot be legally accountable and hence cannot be appointed as directors. Hybrid boardrooms comprising both human and AI directors would also not be feasible since human directors would be likely to conform to the views of super-intelligent machines and hence be unable to exercise independent judgment. Accountability asymmetry would also arise since only the human, but not AI directors, would be accountable for decisions.

33 Enriques and Zetzsche (n 28) 29-33.

34 Ibid 42.

35 Ibid 44-7. 
listed companies be required to make periodic disclosure of tech governance arrangements as a means of elevating relevant governance standards. ${ }^{36}$

These divergent prognoses of technology's impact rest, in large part, on contrasting assumptions as to the speed and nature of technological disruptions. For example, much controversy still surrounds the questions whether Artificial General Intelligence (AGI) (that is, machines capable of performing a wide range of human functions) could ever be developed, and when such development would materialise. ${ }^{37}$ Similarly, predictions of blockchain's impact often fail to take account of the mammoth legal, governance and technological infrastructure that has to be put in place before the technology could realise its full potential. ${ }^{38}$ Accordingly, predictions of the impact of future technology - that boards could be fully automated, or that DLT could facilitate full disclosure leading to complete disintermediation - are necessarily speculative. Unsurprisingly, therefore, much recent scholarship has focused on the implications of technological advances in the context of near-term developments.

Rapid as they are, technological advances are unlikely to enable a complete rewrite of corporate governance rules in the foreseeable future. Nevertheless, such progress is occurring at a rate that requires frequent re-examination of the existing legal and regulatory framework. Directors, in particular, must confront multifaceted challenges as they perform their role in highly uncertain and volatile environments. Assuredly, the responsibilities of directors are set to evolve in tandem with the growth of digitalisation and automation. For example, boards are now expected to articulate strategies for strengthening cyber resilience to ensure a prompt response to, and recovery from, cyber attacks. ${ }^{39}$ As businesses invest more heavily in technology and acquire a greater share of intangible or digital assets, boards will need to develop governance strategies

\footnotetext{
36 Ibid 49-50.
}

37 Although commentators generally agree that AGI is still some distance away, some predict it could happen within our lifetime or by the end of this century: see Navin Joshi, 'How Far Are We From Achieving Artificial General Intelligence?' Forbes (Web Page, 10 June 2019) https://www.forbes.com/sites/cognitiveworld/2019/06/10/ how-far-are-we-from-achieving-artificial-general-intelligence/?sh=17027caa6dc4.

38 See Marco Iansiti and Karim Lakhani, 'The Truth About Blockchain' (JanuaryFebruary 2017) Harvard Business Review. The authors suggest that it may take decades for the right infrastructural support to materialise before blockchain technology could realise its full potential.

39 Australia Securities and Investments Commission, 'Cyber Security Good Practices' (Web Page) https://asic.gov.au/regulatory-resources/digital-transformation/ cyber-resilience/cyber-resilience-good-practices/. This may mean that directors will generally need to gain digital literacy or cyber resilience fluency: Thea Voogt, 'Tall Tree and Digital Literacy: Lessons from Palkon v Homes' (2016) 31 Australian Journal of Corporate Law 344, 355. 
to safeguard new asset classes. ${ }^{40}$ Widespread adoption of AI and Big Data analytics to inform strategic and operational decisions will also necessitate the establishment of AI and data governance committees. Caught in the current of these enlarged responsibilities, directors are necessarily concerned with the risk of greater personal liabilities. To what extent can current liability regimes strike a fair balance between the need for accountability and the fostering of entrepreneurial endeavours? This issue is examined by Brand (Chapter 4), who considers the ethical challenges that technology presents for directors; by Langford (Chapter 5), who considers the challenges presented by technology in the context of continuous disclosure, misleading and deceptive conduct, and data security; and by Lee and Leong (Chapter 6), who consider the personal liability of directors of technology companies for copyright infringement.

Another area of corporate activities poised for technology-enabled change is that of shareholder engagement and empowerment. This theme is explored in this book by Koh (Chapter 7), who considers the potential for technology to enhance shareholder empowerment by giving them better access to information. Relatedly, we have also witnessed the abrupt transition of physical to virtual shareholder meetings since the onset of Covid-19. Digital meetings are often regarded as imperfect substitutes for physical ones ${ }^{41}$ but they could counteract the long-standing problem of shareholder passivity by enabling wider and more proactive participation. ${ }^{42}$ Some also contend that shareholder governance could be strengthened if blockchain or DLT were deployed in stock clearance, settlement and voting systems to reduce transaction costs and improve transparency, security and reliability. ${ }^{43}$ More generally, shareholders stand to be further empowered as corporate communication and

40 Andrea M Matwyshyn, 'Imagine the Intangible' (2009) 34 Delaware Journal of Corporate Law 965. The author argues (at 996-1004) for, inter alia, augmentation of fiduciary principles to incentivise more robust management of such assets.

${ }_{41}$ Shareholders without access to the relevant technology may be prejudiced and a digital platform may inhibit open engagement: see Stuart R Cross, 'Corporate Governance, Information Technology and the Electronic Company in the United Kingdom' (2004) 13 Information Communications Technology Law 117, 124.

42 There is evidence of increased shareholder attendance at digital meetings: see Simon Bryan, 'Is it the End for In-Room Shareholder Meetings?' LUMI (Blog Post, 13 July 2020) https://blog.lumiglobal.com/is-it-the-end-for-in-room-shareholder -meetings. Indeed, the generally positive experience with digital meetings is prompting its adoption as a norm post-pandemic: 'Singapore Open to Virtual Shareholder Meetings Post-Covid-19: MAS', The Straits Times, 20 October 2020.

43 See, eg, George Geis, 'Traceable Shares and Corporate Law' (2018) 113 Northwestern University Law Review 227; Anne Lafarre and Christoph Van der Elst, 'Blockchain Technology for Corporate Governance and Shareholder Activism' (Working Paper No. 390/2018, European Corporate Governance Institute, March 2018). 
information-gathering are rendered more efficacious and efficient by the rise of the Internet and information technology. ${ }^{44}$ But it has also been observed that the power disparity (including information asymmetry) between the board and shareholders is such that no blockchain would be able to remedy. ${ }^{45}$ Nor would technology necessarily resolve problems of rational apathy among retail investors. $^{46}$

More fundamentally, suggestions to empower shareholders through technology inevitably reignite the normative debate about the proper objectives of corporate law. ${ }^{47}$ Though widely assumed as the chief constraint on board discretion, shareholder primacy is nevertheless a contested notion, criticised for its tendency to engender short-termism that destroys, rather than creates, wealth. ${ }^{48}$ In Chapter 8 of this book, Weng, Wu and Shen discuss the rise of successful technology companies that have exerted pressures on the traditional model of shareholder primacy through the use of dual-class share structures. These structures are designed to promote entrepreneurship and innovation by strengthening the voting powers of founders of technology companies, but also threaten to erode shareholder primacy, raising complex questions as to how an appropriate balance of power between shareholders with different rights ought to be struck.

So while technology may improve the speed, accuracy and transparency of various corporate activities, it does not resolve threshold questions of what activities are to be promoted and for whose benefit. The chapters in Part IV revisit this aspect of the corporate governance debate as they evaluate new corporate activities made possible by technological innovation. Godwin (Chapter 11) examines the use of technology in the context of corporate disclosure; Donald (Chapter 12) examines data analytics in the context of assessing a company's actual performance and calculating corporate value; and Abdussalam and Rahim (Chapter 13) examine the use of technology in creating 'non-corporate' organisations.

\footnotetext{
44 Ige Omotayo Bolodeoku, 'Corporate Governance in the New Information and Communication Age: An Interrogation of the Rational Apathy Theory' (2007) 7(1) Journal of Corporate Law Studies 109; Tom Burns, 'Implications of Information Technology on Corporate Governance' (2001) 9 International Journal of Law and Information Technology 21.

45 Spencer J Nord, 'Blockchain Plumbing: A Potential Solution for Shareholder Voting?’ (2019) 21 University of Pennsylvania Journal of Business Law 706, 744.

46 Ibid 746-7.

47 Bruner (n 11).

48 Nord (n 45) 750-3.
} 


\subsection{REGULATORY CHALLENGES}

In addition to presenting challenges for the ways in which corporations are formed and governed, technology presents challenges for the regulation of corporations and their activities. The challenges are both conceptual and taxonomical in nature and have been particularly prominent in the area of technology-enabled corporate financing activities. In the case of initial coin offerings (ICOs), for example, fundamental questions arise as to whether the coins or tokens issued pursuant to an ICO are a commodity that investors buy and sell like any other commodity or whether they are analogous to securities or units in management investment schemes and, accordingly, subject to the relevant disclosure and other requirements. Although some of these challenges have been met through the application of 'regulation by analogy', where the relevant activities have been regulated by reference to conventional categories or frameworks, the result is often sub-optimal. The dilemma is exacerbated by the fact that the same technology can often be used to support activities that have different functions.

This reality - namely, that the same technology can be used to support activities with different functions - has motivated a move towards a functional approach to regulation, where the focus is on the function or effect of the transaction or activity rather than the name or label that is given to it. Even this approach presents a taxonomical challenge, however, as has been seen in the case of Uber - is it a taxi business or just a ride-sharing app?

In particular, technological innovation has seen a move away from entities-based or activities-based regulation towards principles-based regulation, where the focus is on compliance with principles relating to the use of technology in areas such as data security and the need to achieve appropriate outcomes for shareholders and other stakeholders. A key issue in this regard is how regulation should achieve an appropriate balance between investor and consumer protection, on the one hand, and corporate innovation and entrepreneurship, on the other hand. In addition, because it is very difficult - if not impossible - to regulate or impose responsibility on the technology itself, the focus is increasingly being placed on regulating and licensing the use of technology by companies and their human agents. Many of the chapters in this book explore these and related themes. 


\subsection{CHAPTER OUTLINE}

\section{Part I: Corporate Form}

\section{Chapter 2: Susan Watson - Viewing artificial persons in the AI age through the lens of history}

Visions of AI or robo-directors invite speculation about radical governance reform as a non-human board is suggestive of a fundamental alteration of the corporate form. In Chapter 2, Watson challenges this supposition by revisiting the conception of the corporation as a legal fiction. Utilising an historical analysis, Watson demonstrates that the company as persona ficta has always been close to an autonomous system that is separate from human beings. This is particularly so if the company is viewed as a hybrid social-cum-property institution that serves not only the property interests of shareholders but also those of society at large. On that view, the AI board is not so much a revolution, but simply an evolution, of a board comprising natural persons. The chief distinction between the two boards is that the AI board is thought to lack human conscience. As Watson points out, however, a board of human directors does not necessarily operate on the basis of the sum of the moral values of the individual directors. The collective conscience may differ from individual conscience because the board is constrained by its internal decision-making framework and the imperatives of profit maximisation. In light of that, Watson argues that a common framework should determine liability for corporate wrongs. Whether a company is managed by algorithms or constrained human agents, liability for corporate wrongs in a technology-enabled environment should extend not only to the board but also beyond to employees who form part of the company's hierarchy. A broader regime of corporate veil piercing would also be justified since shareholders are ultimately the creators of the legal fiction that perpetrates the wrongdoing.

\section{Part II: Corporate Governance}

The focus of this collection of chapters is on the impact of technology on the internal governance of companies and the ethical implications and responsibilities of boards in relation to the adoption of technology.

\section{Chapter 3: Helen Bird and Natania Locke - The corporate board in an age of collaborative intelligence and complex risk}

In their chapter, Bird and Locke discuss the disruptive effects of technology on organisational design, management structures and board functions. They anticipate that technological advancements will change organisational designs 
- from hierarchical management structures to flatter management structures - and will lead to alternative organisational forms with enhanced adaptive capabilities and internal information flow. AI will facilitate this evolution as it relieves management substantially of routine administrative work and augments the quality of judgment work. However, a rapid transition to decentralised forms is, in the authors' view, unlikely given the immense complexity of the process. Bird and Locke foresee the advent of 'fused boards' comprising human actors assisted extensively by AI but categorically reject the vision of fully automated boards. In their view, companies will always require 'humans in the loop' to provide accountability and oversight. The sheer enormity and complexity of the board's functions in providing oversight and leadership will require continued human involvement, not least because the AI systems must themselves be monitored by human actors to ensure continued efficacy. Contrary to Petrin's suggestion, Bird and Locke do not think that shareholders could substitute the board in providing oversight and leadership - they have neither the expertise nor willingness (in expending resources) to do so. Like Enriques and Zetzsche, Bird and Locke are sceptical of claims that AI will completely overcome agency problems since there will always be humans involved in their development and operation. In their view, the board will continue to exercise oversight albeit with increased AI assistance. Moreover, the leadership function will always remain the sole purview of the (human) board simply because code will never be able to discern purpose. Bird and Locke conclude with a case study of AUSTRAC $v$ Westpac to illustrate the issues discussed.

\section{Chapter 4: Vivienne Brand - Artificial intelligence and corporate boards: some ethical implications}

AI may be unlikely to replace human directors anytime soon, but its application in business processes is set to grow. In tandem with that, corporate boards must be prepared to confront complex legal and ethical issues associated with the deployment of AI in corporate operations and management. In her chapter, Brand recounts the diverse ethical issues presented by AI systems and the limits of ethical guidelines promulgated for AI development. Citing Mittelstadt, Brand observes that such guidelines are generally deficient because they tend to adopt a 'principles-based' approach, comprising high-level norms that are not easily reducible to specific guidance for complex, situated and nuanced judgments that directors are required to make. However, Brand suggests that this gap can be bridged by existing legal duties owed by directors, namely, the duty of care and the duty to act in good faith in the company's best interests. The former provides a familiar mechanism for making situated judgments and trade-offs, while the latter furnishes additional incentives for directors to address the ethical implications of their decisions. The obligation of direc- 
tors to address ethical concerns is further reinforced by the trend towards a stakeholder-centric conception of the company's interests (requiring directors to consider the interests of a broader group of stakeholders beyond those of shareholders) and attention to corporate reputation as an element of duty of care. Brand concludes that these existing duties may 'offer surprisingly useful guidance for directors' as they confront 'the brave new world of AI' ${ }^{49}$

\section{Chapter 5: Rosemary Teele Langford - Data explosion, disclosure and stepping stones}

Langford's chapter builds on a theme explored in Brand's chapter - namely, the extent to which directors' duties are impacted by the challenges presented by technology - by examining the statutory duty of care in the context of continuous disclosure, misleading and deceptive conduct and data security. In particular, Langford examines the concept of stepping stones liability and its role in cases involving breaches of continuous disclosure and argues that stepping stones liability should be treated as a straightforward application of the duty of care (or other duty). Langford outlines the challenges that technology present for directors in discharging their duty of care in relation to continuous disclosure and notes the relevance of this mode of liability in other jurisdictions.

Langford's analysis reminds us that technology is not only creating challenges for directors in discharging their traditional duties; it is also requiring us to reconceptualise these duties and the role that they play in the context of board governance.

\section{Chapter 6: Pey Woan Lee and Susanna HS Leong - Recalibrating directors' liabilities amidst technological flux}

In line with one of the key themes of this book, Lee and Leong consider how the balance ought to be struck between corporate innovation and personal liability. The authors explore this theme in the specific context of directors' exposure to personal liability for corporate copyright infringements. They observe that both the statutory and common law regimes imposing personal liability on directors are currently ambivalent and unsatisfactory, principally because of the tension between conflicting policy goals of encouraging innovation while preserving personal accountability. Delving into the modern history of copyright law development, the authors seek to demonstrate that directors of technological companies operate in an environment of high legal uncertainty as the law constantly lags behind rapid scientific innovation. They argue, therefore, that the dynamic environment in which technological businesses operate justifies a restrictive approach towards the imposition of personal liability.

\footnotetext{
49 Brand, Chapter 4 in this book, 98.
} 
Although made in the specific context of copyright infringements, their analysis informs the broader discourse on the impact of technology on corporate governance. They surmise that "personal liability may decline in significance as a regulatory tool when public interests in innovation and enterprise take precedence, and that technological innovation may itself require legal innovation' ${ }^{50}$

\section{Part III: Governance Democratisation}

A key theme of this Part is the impact of technology in changing and recalibrating the relationship between companies and their stakeholders.

\section{Chapter 7: Pearlie Koh - Shareholder empowerment in the digital age}

The first chapter in Part III considers the balance of power in companies between managers (directors) and owners (shareholders) and examines the potential for technology to enhance shareholder empowerment through giving them better access to information and revolutionising the way in which they interact and communicate amongst themselves. Koh argues that the impact of technology on the potential corporate governance role of minority shareholders can be significant; however, questions remain such as the accuracy and adequacy of information and whether shareholders are adequately equipped to fulfil an enhanced governance role. Koh reminds us that the effectiveness of technology in a corporate context depends on its ability to resolve age-old challenges, such as information asymmetry, and that the benefits of innovation must be assessed by reference to the outcomes that it achieves. Once again, our attention is drawn to the need to maintain our focus on fundamental principles of corporate law and corporate governance.

\section{Chapter 8: Charlie Xiao-chuan Weng, Shangxuan Wu and Zhaohui} Shen - The first step of a long march: dual-class company regulation and the experiment by the sci-tech and innovation board in China

Weng, Wu and Shen examine the same big-picture question examined by Koh; namely, how to strike an appropriate balance of power between the stakeholders in companies and how to calibrate corporate governance accordingly. Their chapter, however, approaches the issues from the perspective of the founders of technology and innovation companies. In particular, the authors assess the relative merits of the dual-class share structure in strengthening the voting powers of founders and creating suitable conditions for entrepreneurship and innovation, and examine the challenges that this structure presents for corpo-

\footnotetext{
50 Lee and Leong, Chapter 6 in this book, 127-8.
} 
rate governance. These challenges are considered from a theoretical perspective, by reference to the existing literature on the dual-class share structure and, from a practical perspective, by reference to recent developments and efforts in China. The authors note that any reforms must take account of conventional issues such as achieving appropriate investor protection outcomes. Once again, we are reminded of the need to maintain our focus on fundamental principles of corporate law and corporate governance. The chapter also invites us to reflect on a common agency problem; namely, the inherent conflicts of interest between dominant and minority shareholders.

\section{Chapter 9: Aurelio Gurrea-Martínez and Nydia Remolina - Corporate governance challenges in initial coin offerings}

Gurrea-Martínez and Remolina explore the impact of technology in terms of creating new sources of finance and new stakeholders; specifically, ICOs and token-holders respectively. In particular, the chapter goes beyond the previous focus in the literature on the regulation of ICOs themselves and plugs a gap by analysing the corporate governance and investor protection challenges as they relate to token-holders. After outlining the exacerbated agency problems between the issuers and buyers of tokens and the regulatory vacuum in this regard, the chapter makes various policy recommendations to enhance the protection for token-holders and to create greater certainty for entrepreneurs. The chapter argues that traditional corporate governance mechanisms do not work for ICOs and that new strategies are required to protect token-holders, irrespective of the status that they might have from a functional or legal perspective. In highlighting the challenges presented by ICOs, Gurrea-Martínez and Remolina draw our attention to both the limitations and strengths of traditional corporate governance mechanisms and the need to ensure appropriate outcomes where technology creates new sources of finance and new stakeholders.

\section{Chapter 10: Steve Kourabas - Corporate governance implications of equity crowdfunding}

In his chapter, Kourabas examines the opportunities and corporate governance challenges presented by technology through the new platform for conventional corporate equity finance that is called 'equity crowdfunding'. The opportunity that equity crowdfunding presents for micro, small and medium enterprises to raise finance from a widely dispersed group of shareholders has necessitated exemptions from the traditional requirements that apply to a public offer of shares and has introduced a public financing dimension into private corporations. It has also created a new category of investors who are motivated to invest through a combination of potential financial return and the prospect of being part of a project that benefits the community. Similarly to Gurrea-Martínez and Remolina in their analysis of ICOs, Kourabas explores the difficulties in 
applying traditional corporate governance frameworks to equity crowdfunding and identifies the need to move beyond the director-shareholder narrative of the Berle and Means Corporation. In particular, Kourabas argues that governance mechanisms that give shareholders a 'voice' on matters other than the financial management of the corporation are necessary to help maximise the 'community benefit' promise of equity crowdfunding. Accordingly, Kourabas calls for enhanced communication facilities, detailed purpose clauses in the constitutions of companies and investor feedback mechanisms. Similarly to the chapter by Watson and the chapter by Bird and Locke, Kourabas' chapter provokes us to revisit and rethink the purpose of a corporation and the internal governance structures of the corporation as traditionally understood.

\section{Part IV: Data Enhancements and Alternative Models for 'Corporate' Governance}

A key theme of Part IV is the potential for technology, specifically data technology and DLT, to transform the ways in which companies and business organisations are regulated, valued and conceived for governance purposes.

\section{Chapter 11: Andrew Godwin - Corporate disclosure in a technology-enabled world}

In his chapter, Godwin explores the use of regulatory technology (or 'RegTech') by corporate regulators to help them perform their regulatory and supervisory functions. Specifically, Godwin considers the use of AI techniques such as natural language processing to assess compliance by companies with disclosure requirements and the legal and regulatory implications that arise as a result. The analysis examines four questions: (1) whether technology will change the way in which disclosure language is interpreted; (2) whether technology will change the language of disclosure itself; (3) whether regulators will be able to maintain transparency in their use of technology; and (4) how to maintain an appropriate degree of human involvement and guarantee trust in the process. Godwin highlights the challenges presented by AI, including the opacity caused by the 'black box' problem as previously explored by Brand, and the need to achieve an appropriate balance between technology and human involvement as previously explored by Bird and Locke. Just as human judgment will continue to be relevant in decision-making in companies, human judgment will continue to be relevant in supervision and decision-making by corporate regulators. The analysis also reinforces the reality that the complete substitution of technological solutions for corporate law is still a distant prospect. 


\section{Chapter 12: David C Donald - Keep your 'invisible hands' to yourself:} freeing corporate governance from the cult of the 'efficient market'

Along similar lines to Kourabas, Donald's chapter draws our attention back to fundamental issues of corporate law and corporate governance, including the purpose of a corporation as a vehicle for conducting productive activity. In particular, Donald exposes the fallacies of binding corporate governance to secondary market trading and the 'fading fable of perfect pricing efficiency'. Arguing that '[c] orporate governance design should be disentangled from the imperatives of securities trading and be refocused on strengthening a company's actual performance in the product or services market, as is generally done in the context of venture capital (VC) investment', ${ }^{51}$ Donald's chapter explains how data analytics can provide a more accurate basis for assessing a company's actual performance and calculating corporate value. It also encourages us to reflect on how data analytics and technology more generally can assist in strengthening modern corporate governance and achieving its original aims.

\section{Chapter 13: Moshood Abdussalam and Mia Rahim - The advent of decentralised autonomous business networks in the disembodied economy: a discussion on why the governance regimes of corporations and partnerships are unsuitable to them}

In the final chapter in this book, Abdussalam and Rahim explore an emerging alternative to the corporation as a form of business organisation - decentralised autonomous business networks (DABNs) - and outline the ways in which these networks are replacing market competition with cooperation in the 'disembodied economic era', enabling 'business and people to create, transmit, manage, exploit and consume value in decentralised form' ${ }^{52}$ In contrast with Watson's chapter, which examines the governance challenges presented by technology within the conventional corporate form, Abdussalam and Rahim's chapter analyses the governance challenges within technology-enabled, 'non-corporate' organisations. Through the lenses of ownership, management and legal responsibility, Abdussalam and Rahim argue that neither the corporate nor partnership regime of business governance should be adopted for DABNs. Instead, the law should treat DABNs as akin to unincorporated associations and as 'a web of interlinked contracts between participating nodes, under which assets and liabilities are, respectively, held and attributed in a fashion similar to that of unincorporated associations'. ${ }^{53}$ Although taking us outside the confines of corporations and the relative comfort that can be

51 Donald, Chapter 12 in this book, 283.

52 Abdussalam and Rahim, Chapter 13 in this book, 309.

53 Ibid 310. 
found in 'corporate' governance, Abdussalam and Rahim's analysis reminds us of the continuing importance of traditional governance principles and also the ongoing relevance of 'corporate law' (as broadly conceived) in the context of innovation and technology. 